\title{
THE EFFECT OF ALTERATIONS IN ACTIVITY AND BODY TEMPERATURE ON THE PULMONARY SURFACTANT SYSTEM IN THE LESSER LONG-EARED BAT NYCTOPHILUS GEOFFROYI
}

\author{
NICOLA C. SLOCOMBE, JONATHAN R. CODD, PHILIP G. WOOD, SANDRA ORGEIG \\ AND CHRISTOPHER B. DANIELS* \\ Department of Environmental Biology, University of Adelaide, Adelaide, South Australia 5005, Australia \\ *Author for correspondence (e-mail: christopher.daniels@ adelaide.edu.au)
}

Accepted 23 May; published on WWW 20 July 2000

\begin{abstract}
Summary
Pulmonary surfactant is a mixture of phospholipids, neutral lipids and proteins that controls the surface tension of the fluid lining the lung. It is critical for lung stability and function. The amount and composition of surfactant are influenced by physiological variables such as metabolic rate, body temperature and ventilation. We investigated the plasticity of the pulmonary surfactant system in the microchiropteran bat Nyctophilus geoffroyi throughout a natural $24 \mathrm{~h}$ cycle. Bats were housed at $24^{\circ} \mathrm{C}$ on a fixed $(8 \mathrm{~h}: 16 \mathrm{~h})$ light:dark photoperiod. At $4 \mathrm{~h}$ intervals

of activity, at 18:00 $\mathrm{h}$ and 06:00 $\mathrm{h}$. The amount of surfactant increased 1.5-fold upon arousal from torpor. The proportion of DSP to $P L$ in the surfactant remained constant. Similarly, the Chol/PL and Chol/DSP ratios remained relatively constant. Surfactant cholesterol content did not increase during torpor in $N$. geoffroyi. Cholesterol does not appear to control surfactant fluidity during torpor in these bats, but instead the cholesterol content exactly mirrored the diurnal changes in body temperature.
\end{abstract} throughout the $24 \mathrm{~h}$ period, bats were lavaged and the surfactant analysed for absolute and relative amounts of total phospholipid (PL), disaturated phospholipid (DSP) and cholesterol (Chol). $N$. geoffroyi experienced two peaks

Key words: torpor, arousal, cholesterol, phospholipid, lesser longeared bat, Nyctophilus geoffroyi.

\section{Introduction}

Pulmonary surfactant is a complex mixture of surface-active phospholipids (PLs), neutral lipids and specific proteins. The surface-active component of surfactant is the disaturated phospholipid dipalmitoylphosphatidylcholine (DPPC), which forms a monolayer at the air-liquid interface and can virtually abolish surface tension during compression at low lung volumes (Veldhuizen et al., 1998). The dynamic compression of the monolayer is thought to selectively exclude other components, leaving a DPPC-enriched film. At $37^{\circ} \mathrm{C}$, this would be below the phase transition point and consequently DPPC adsorbs very slowly to a surface (Veldhuizen et al., 1998). It appears that unsaturated phospholipids and cholesterol are required to convert the DPPC from its gel form to the more spreadable disordered state. In the liquidcrystalline state, the lipids can disperse to coat the surface of the expanding fluid layer (Possmayer, 1991).

Surfactant is stored, synthesised and released from cuboidal epithelial type II cells (Goerke, 1998). Surfactant within the type II cells is stored in lamellar bodies. Upon an appropriate signal, the lamellar bodies are exocytosed into the alveolar space, forming a surface film (Goerke, 1998). In mammals, mechanical distortion of the type II cell is an important stimulator for surfactant release (Wirtz and Dobbs, 1990). Type II cells are found in the corners and crevices of the alveoli, where they can respond to distortion of the cell and hence respond rapidly to changes in breathing pattern (Wright and Clements, 1989). Adrenergic agonists will also stimulate surfactant release by acting directly on $\beta_{2}$ receptors on the cell membrane (Brown and Longmore, 1981). Acetylcholine is thought to stimulate surfactant release indirectly by acting on the adrenal medulla in eutherian mammals (Brown and Longmore, 1981). Our laboratory has recently determined that acetylcholine triggers surfactant secretion from isolated type II cells of ectothermic and heterothermic animals such as lizards, dunnarts, frogs and lungfish by acting directly on cholinergic receptors on the cells (Wood et al., 1999, 2000). Cholinergic stimulation may persist in heterothermic and ectothermic animals to allow secretion to continue at low body temperatures.

Temperature has profound effects on the amounts and composition of surfactant. In both the central Australian lizard Ctenophorus nuchalis and a dasyurid marsupial, the fat-tailed dunnart Sminthopsis crassicaudata, a decrease in body temperature (to below $20^{\circ} \mathrm{C}$ ) was associated with absolute and 
relative increases in the amount of cholesterol in the surfactant (Daniels et al., 1990; Langman et al., 1996). Torpor in $S$. crassicaudata was also associated with an increase in the absolute and relative amounts of disaturated phospholipid (Langman et al., 1996). Since these animals also experienced marked changes in breathing pattern, it remains unclear whether the alterations are due to a direct influence of temperature or are mediated by changes in breathing pattern.

In the bearded dragon Pogona vitticeps, both an increase in body temperature (from 18 to $37^{\circ} \mathrm{C}$ ) and exercise are associated with a marked increase in surfactant phospholipid levels (Wood et al., 1997), yet changes in ventilation in the isolated perfused lung had no effect on surfactant amounts or composition (Wood et al., 1995). Swimming and cycling exercise in rats and humans, respectively, also results in increases in surfactant amounts and moderately alters the cholesterol to disaturated phospholipid ratio of alveolar surfactant (Doyle et al., 1994; Orgeig et al., 1995). Presumably, increases in temperature and exercise may directly stimulate surfactant release by increasing the metabolic rate of the type II cell and, hence, the rate of synthesis and/or exocytosis of the lamellar bodies. Alternatively, they may act indirectly by increasing plasma levels of adrenaline and noradrenaline (Wood et al., 1997).

The pulmonary surfactant system is controlled by numerous physiological factors that interact with and influence each other. Furthermore, in heterothermic animals, these physiological variables are subject to profound fluctuations over the course of $24 \mathrm{~h}$. For example, throughout the natural daily cycle of the microchiropteran bat Nyctophilus geoffroyi, there are rapid physiological changes. Bats undergo the transition from torpor, which is associated with body temperatures below $30^{\circ} \mathrm{C}$ and significant depressions in metabolic rate and ventilation, to flight, which is accompanied by a profound increase in ventilation and may be associated with an increase in body temperature above $37^{\circ} \mathrm{C}$ (Thomas, 1981; Thomas et al., 1984). These profound physiological changes have the potential to compromise the functioning of the pulmonary surfactant system. Here, we examine the responses of the pulmonary surfactant system to diurnal fluctuations in body temperature and activity levels in these bats.

\section{Materials and methods} Animals

Nyctophilus geoffroyi were trapped using harp traps in the Flinders Ranges, South Australia, over the summer/autumn period from February to May 1999. They were housed at the University of Adelaide at a constant ambient temperature of $24{ }^{\circ} \mathrm{C}$. The walls of the 'bat house' were partially covered with hessian to allow the bats to roost naturally. The diet of the bats included mealworms (Tenebrio molitor) and crickets (Acheta domestica), which were always available and supplemented daily. Water was supplied ad libitum. Thirty-six adult male $N$. geoffroyi were used. Body mass, forearm length and foot length were recorded at the start of each experiment. For $N$. geoffroyi, body mass ranged from 4.91 to $12.44 \mathrm{~g}(7.5 \pm 0.28 \mathrm{~g})$, mean forearm length was $36.33 \pm 0.3 \mathrm{~mm}$ and mean foot length was $6.38 \pm 0.2 \mathrm{~mm}$ (means \pm S.E.M.).

\section{Experimental protocol}

At intervals of $4 \mathrm{~h}$ over a $24 \mathrm{~h}$ period, the metabolic rate of at least six bats was measured, and six different bats were killed and lavaged for surfactant analysis. The percentage of bats observed as torpid and warm-active was also recorded at each time point using a criterion of $T_{\mathrm{b}} \leqslant 28^{\circ} \mathrm{C}$ for torpor in $N$. geoffroyi (Speakman, 1988).

\section{Metabolic rate}

Bats were placed in a 11 clear Perspex metabolic chamber divided by a partition covered in stainless-steel mesh that allowed the bat to roost naturally and to minimise stress. The mesh partition created an area of $150 \mathrm{ml}$ in which the bat was housed and from which measurements were taken within 1 min of the bat entering the chamber. Fresh air entered the chamber from small inlet ports. Air outflow from the chamber was connected to an infrared $\mathrm{CO}_{2}$ and Zirconia cell $\mathrm{O}_{2}$ analyser. Air was then pumped through the gas analyser by a pump connected to a flowmeter calibrated to a flow rate of $500 \mathrm{ml} \mathrm{min}^{-1}$ (accurate to 0.005 of $1 \%$ ). The high flow rate ensured rapid 'plateau' levels of $\mathrm{O}_{2}$ within $30 \mathrm{~s}$. The $\mathrm{O}_{2}$ and $\mathrm{CO}_{2}$ measurements were made each minute for the first $3 \mathrm{~min}$ the bat was in the chamber. The rate of oxygen consumption $\dot{V}_{\mathrm{O}_{2}}\left(\mathrm{ml} \mathrm{min}{ }^{-1}\right.$ at STPD) was then calculated using a modification of the Haldane equation for an open-flow system (Frappell and Daniels, 1991):

$$
\begin{gathered}
\dot{V}_{\mathrm{O}_{2}}=V \mathrm{IO}_{2}-V \mathrm{EO}_{2}, \\
\dot{V}_{\mathrm{O}_{2}}=\frac{\dot{\mathrm{E}}\left[1-\left(F \mathrm{E} C O_{2}+F \mathrm{EO}_{2}\right)\right] F \mathrm{IO}_{2}-\dot{V} \mathrm{E} F \mathrm{EO}_{2}}{1-\left(F \mathrm{ICO}_{2}+F \mathrm{IO}_{2}\right)},
\end{gathered}
$$

where $\mathrm{VIO}_{2}$ and $\mathrm{VE}_{2}$ are the volume of inspired and expired oxygen, respectively, $\mathrm{FECO}_{2}$ and $\mathrm{FEO}_{2}$ are the fractional concentrations of $\mathrm{CO}_{2}$ and $\mathrm{O}_{2}$, respectively, in the expired air, $F_{\mathrm{ICO}_{2}}$ and $\mathrm{FIO}_{2}$ are these respective concentrations in the inspired air and $\dot{E}$ is flow.

An infrared laser-sighted thermometer was used to measure body temperature (to $\pm 1^{\circ} \mathrm{C}$ ) non-invasively prior to measuring metabolic rate. $T_{\mathrm{b}}$ was again measured after completing the metabolic rate measurements and before the bat was released into the bat room. If $T_{\mathrm{b}}$ increased during the period in which metabolic measurements were taken, indicating that the bats were becoming stressed or arousing from torpor, only the $\dot{V}_{\mathrm{O}_{2}}$ from the first minute was used in subsequent analyses. If $T_{\mathrm{b}}$ remained stable, the $\dot{V}_{\mathrm{O}_{2}}$ data from the third minute were used to best represent 'steady-state' $\dot{V}_{\mathrm{O}_{2}}$.

\section{Lavage procedure}

Animals were killed by an intraperitoneal overdose of sodium pentabarbitone $\left(0.1 \mathrm{ml}, 325 \mathrm{mg} \mathrm{ml}^{-1}\right)$, and the trachea was exposed and cannulated. Rectal body temperature was measured prior to experimentation (to within $\pm 0.1^{\circ} \mathrm{C}$ ). The 
lungs were then lavaged with ice-cold $0.15 \mathrm{moll}^{-1} \mathrm{NaCl}$. Three consecutive volumes (of $1 \mathrm{ml}$ ) were infused and withdrawn three times from a syringe filled with $2 \mathrm{ml}$ of saline. Lavage material was then centrifuged at $150 \mathrm{~g}$ for 5 min (Beckman model TJ-6) to pellet macrophages and cellular debris. Following lavage, the lungs were removed and freeze-dried for determination of dry lung mass.

\section{Biochemical analyses}

Lipids were extracted with chloroform/methanol (1:2), and total phospholipid was determined using our standard protocols (Wood et al., 1997). Phospholipid amounts were expressed in $\mathrm{mg} \mathrm{g}^{-1}$ dry lung mass. Disaturated phospholipids and neutral lipids were extracted using absorption column chromatography (Wood et al., 1997).

The cholesterol content of the neutral lipid fraction was measured using a high-performance liquid chromatography (HPLC) system (Lopatko et al., 1999) comprising an LKB 2157 autosampler (Pharmacia LKB Biotechnology, Uppsala, Sweden) and a Waters pumping system (model M-45, Waters, Milford, MA, USA). Either standard or sample $(70 \mu \mathrm{l})$ was injected into a Waters ${ }^{18} \mathrm{C}$ Novopak guard and analytical column $(150 \mathrm{~mm} \times 4.6 \mathrm{~mm}$ i.d. $)$ packed with $4 \mu \mathrm{m}$ spherical silica. Isocratic elution of cholesterol was completed within $30 \mathrm{~min}$ at room temperature $\left(23^{\circ} \mathrm{C}\right)$ using a mobile phase of acetonitrile-190, isopropanol and water (6:3:3). Ultraviolet absorbance was monitored at $210 \mathrm{~nm}$ in a model 481 Lambda Max LC spectrophotometer (Waters, Milford, MA, USA).

\section{Data analysis}

Statistical analyses of $\dot{\mathrm{V}}_{2}$ values and surfactant lipid composition data (absolute and relative amounts of total phospholipid, disaturated phospholipid and cholesterol) were performed using a one-way analysis of variance (ANOVA) followed by post-hoc $t$-tests. Results are expressed as means \pm S.E.M. Ratios were arcsine-transformed prior to analysis. Time points were compared only with the one adjacent, such that the peaks and troughs of the graphs could be examined. This limited the overall number of tests performed, and a Bonferroni inequality was not therefore necessary to control type I error rate.

\section{Results}

\section{Body temperature}

The body temperature of $N$. geoffroyi underwent significant variations during the course of $24 \mathrm{~h}$ (Figs 1A, 2A). Body temperature $\left(T_{\mathrm{b}}\right)$ peaked between $18: 00 \mathrm{~h}$ and $22: 00 \mathrm{~h}$ and again at $06: 00 \mathrm{~h}$. The lowest $T_{\mathrm{b}}$ values were recorded at $02: 00 \mathrm{~h}$ and $10: 00 \mathrm{~h}$. The mean torpid $T_{\mathrm{b}}, 25 \pm 0.52^{\circ} \mathrm{C}$, was significantly lower than the mean warm-active $T_{\mathrm{b}}$, which was $32.65 \pm 0.53{ }^{\circ} \mathrm{C}$. Minimum and maximum $T_{\mathrm{b}}$ values were $25^{\circ} \mathrm{C}$ and $36.8{ }^{\circ} \mathrm{C}$, respectively. The $T_{\mathrm{b}}$ values obtained for $N$. geoffroyi were similar to those obtained for this species by Hosken and Withers (1999) (Fig. 2A).
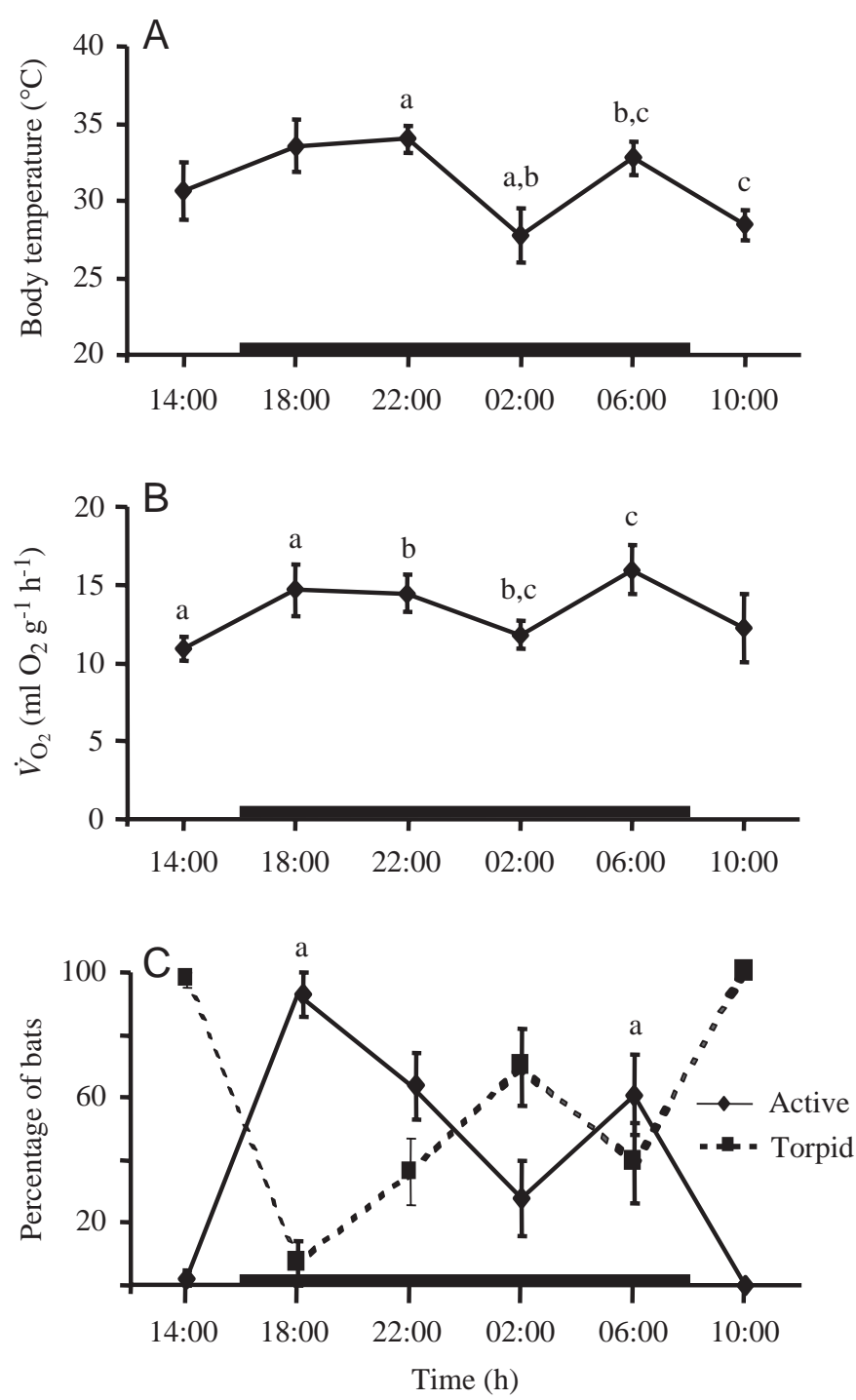

Fig. 1. Diurnal changes in (A) body temperature, (B) metabolic rate $\left(\dot{V}_{\mathrm{O}_{2}}\right)$ and $(\mathrm{C})$ percentage of the bat colony observed as either torpid or warm-active for Nyctophilus geoffroyi at an ambient temperature, $T_{\mathrm{a}}$, of $24^{\circ} \mathrm{C}$. Bats observed as 'torpid' were motionless, curled up and slow to respond to human touch. Those observed as 'warmactive' were alert and/or flying. The horizontal dark bars represent the period of darkness. Identical letters indicate points that are significantly different at $P \leqslant 0.05$. Values are means \pm S.E.M.; $N=5-6$ for each point in $\mathrm{A}$ and $\mathrm{B}$, and $N=36$ for each point in $\mathrm{C}$.

\section{Metabolic rate}

The $\dot{V}_{\mathrm{O}_{2}}$ of $N$. geoffroyi underwent significant variations during this study (Figs 1B, 2B). $\dot{\mathrm{O}}_{2}$ peaked between 18:00 h and $22: 00 \mathrm{~h}$ and again at $06: 00 \mathrm{~h}$. The lowest $\dot{V}_{\mathrm{O}_{2}}$ values occurred at $02: 00 \mathrm{~h}$ and $14: 00 \mathrm{~h}$. Mean $\dot{V}_{\mathrm{O}_{2}}$ for torpid bats, $11.34 \pm 0.59 \mathrm{ml} \mathrm{O}_{2} \mathrm{~g}^{-1} \mathrm{~h}^{-1}$, was significantly lower than that of warm-active bats, which was $14.32 \pm 0.84 \mathrm{ml} \mathrm{O}_{2} \mathrm{~g}^{-1} \mathrm{~h}^{-1}$. Minimum and maximum $\dot{V}_{\mathrm{O}_{2}}$ values were $5.26 \mathrm{ml} \mathrm{O}_{2} \mathrm{~g}^{-1} \mathrm{~h}^{-1}$ and $23.96 \mathrm{ml} \mathrm{O}_{2} \mathrm{~g}^{-1} \mathrm{~h}^{-1}$, respectively, representing a maximum possible change in $\dot{\mathrm{O}}_{2}$ of 4.5 -fold and a maximum energetic saving in torpor of $78 \%$. The $\dot{V}_{\mathrm{O}_{2}}$ values were consistently 

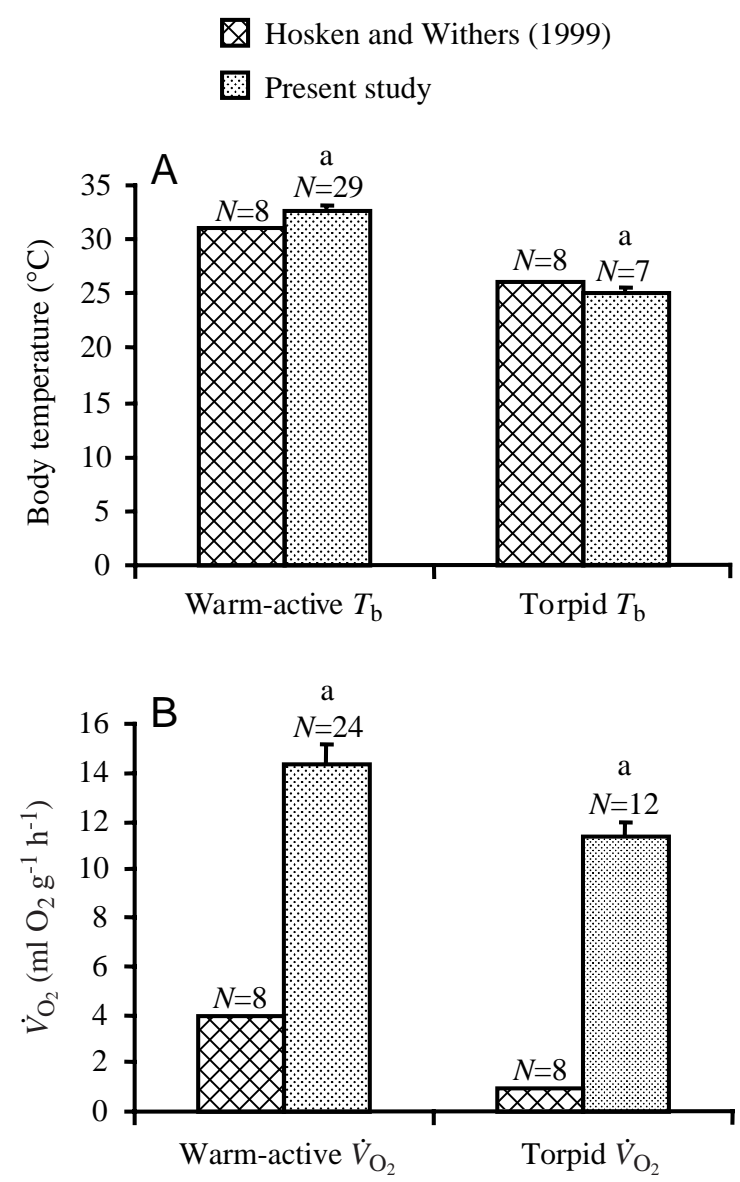

Fig. 2. (A) Comparison of body temperature values from the present study with those of Hosken and Withers (1999) for Nyctophilus geoffroyi at an ambient temperature, $T_{\mathrm{a}}$, of $24^{\circ} \mathrm{C}$. Bats were classified as torpid at $T_{\mathrm{b}} \leqslant 28^{\circ} \mathrm{C}$ (Speakman, 1988). (B) Comparison of $\dot{V}_{\mathrm{O}_{2}}$ measurements from the two studies. Values are means + S.E.M. for the present study data. Identical letters refer to significant differences $(P<0.05)$ between torpid and warm-active bats in the present study.

higher than those obtained by Hosken and Withers (1999) (Fig. 2B), although the maximum possible change in $\dot{\mathrm{V}}_{2}$ of 4.5-fold was similar to that of Hosken and Withers (1999).

The percentage of warm-active bats increased with increasing $T_{\mathrm{b}}$ and $\dot{\mathrm{V}}_{2}$ (Fig. 1C). At $18: 00 \mathrm{~h}, 93 \%$ of the bats were warm-active and at $06: 00 \mathrm{~h}, 61 \%$ were warm-active. Bats were significantly more active at $18: 00 \mathrm{~h}$ and $06: 00 \mathrm{~h}$ compared with adjacent time points (Mann-Whitney $U, P<0.05$ ). Almost all the bats were torpid during the light phase. At $02: 00 \mathrm{~h}$, when $T_{\mathrm{b}}$ and $\dot{\mathrm{V}}_{\mathrm{O}_{2}}$ were relatively low, $28 \%$ of the bats remained warm-active.

\section{Surfactant lipids}

The total amount of phospholipid measured in the lavage varied significantly over the course of $24 \mathrm{~h}$ (Fig. 3A). Upon arousal from torpor, between 14:00 $\mathrm{h}$ and $18: 00 \mathrm{~h}$, there was a 1.8-fold increase in phospholipid levels and an increase in metabolic rate. This relatively high level of phospholipid was
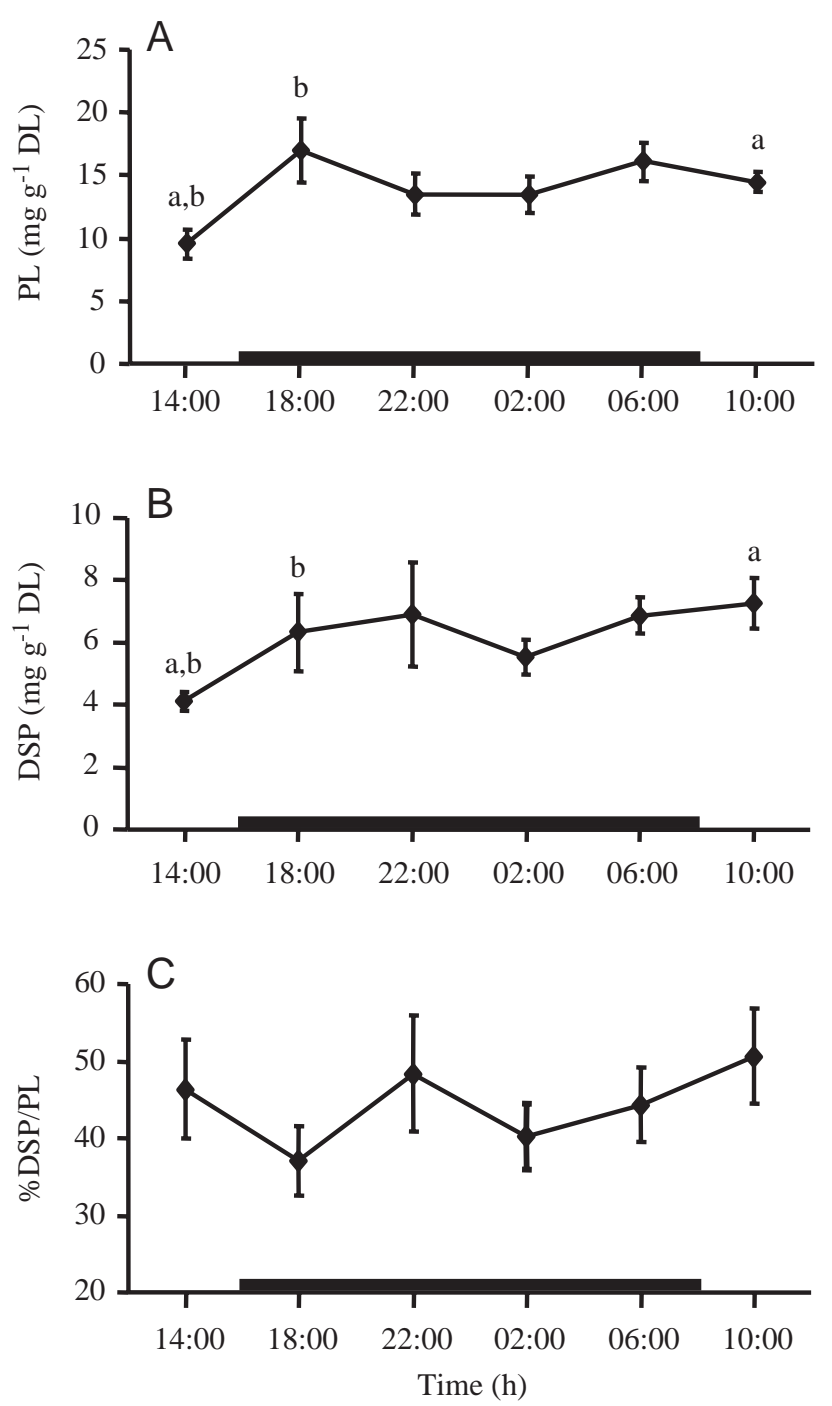

Fig. 3. Diurnal changes in (A) total phospholipid (PL) content of lavage, (B) total disaturated phospholipid (DSP) content of lavage and (C) percentage of phospholipid that is disaturated phospholipid in Nyctophilus geoffroyi at an ambient temperature, $T_{\mathrm{a}}$, of $24^{\circ} \mathrm{C}$. Amounts are expressed per gram dry lung mass. The horizontal dark bars represent the period of darkness. Identical letters indicate points that are significantly different at $P \leqslant 0.05$. Values are means \pm S.E.M.; $N=5-6$ for each time point.

maintained until 10:00 h, after which PL levels decreased to reach values of around $10 \mathrm{mg} \mathrm{g}^{-1}$ dry lung mass at $14: 00 \mathrm{~h}$.

The total amount of disaturated phospholipid (DSP) measured in the lavage also varied significantly over the course of $24 \mathrm{~h}$ (Fig. 3B). The amount of disaturated phospholipid increased 1.5-fold between 14:00 $\mathrm{h}$ and 18:00 $\mathrm{h}$. The relatively high levels of disaturated phospholipid were maintained until 10:00 h, after which levels decreased. Diurnal changes in disaturated phospholipid were similar to the diurnal changes in total phospholipid, such that the DSP/PL ratio did not vary significantly at any stage during the $24 \mathrm{~h}$ cycle (Fig. 3C).

Diurnal changes in the measured amount of cholesterol exactly mirrored the diurnal changes in body temperature 

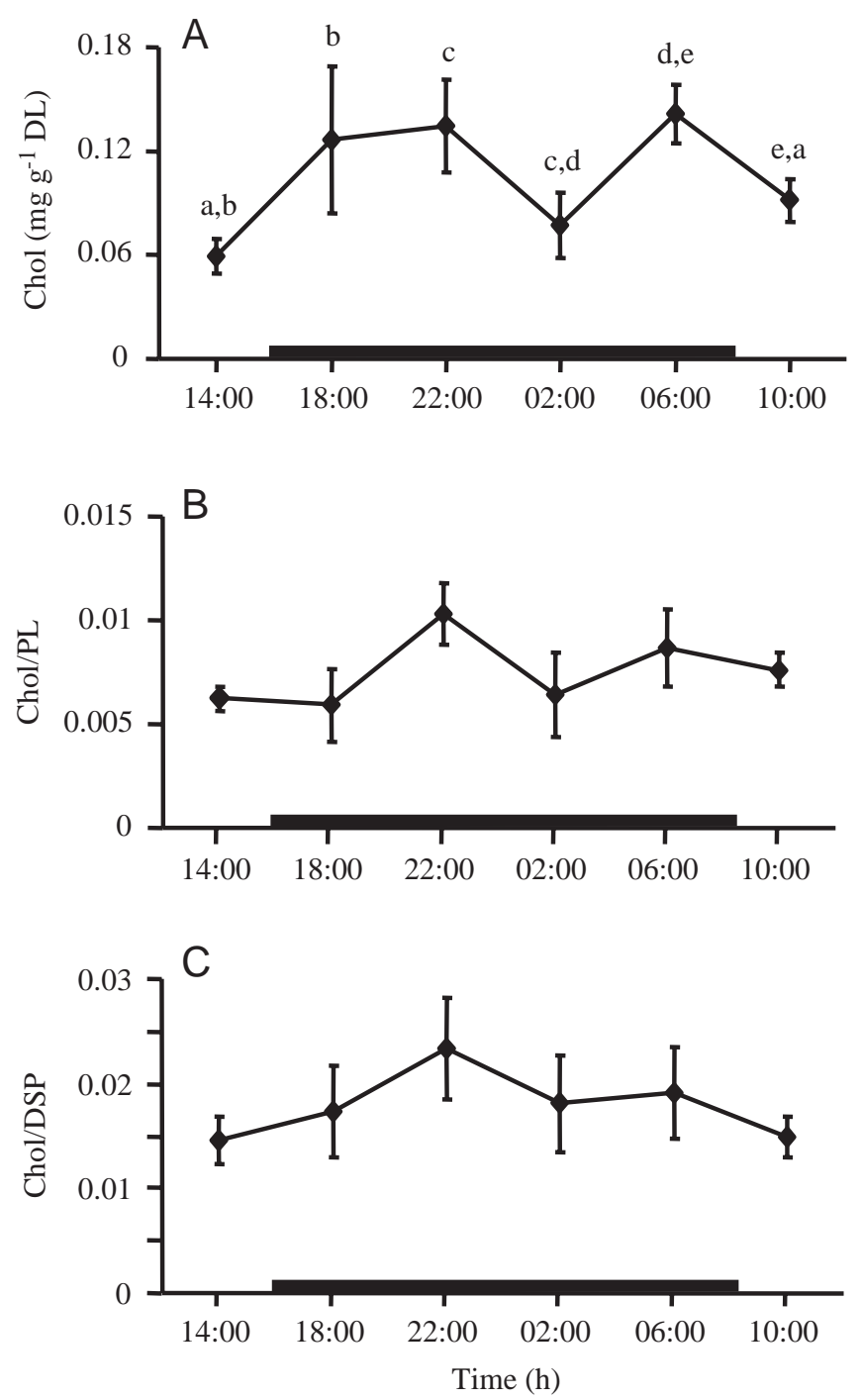

Fig. 4. Diurnal changes in (A) cholesterol (Chol) content of lavage per gram dry lung mass, (B) cholesterol content relative to phospholipid (PL) content and (C) cholesterol content relative to disaturated phospholipid (DSP) content in Nyctophilus geoffroyi at an ambient temperature, $T_{\mathrm{a}}$, of $24^{\circ} \mathrm{C}$. The horizontal dark bars represent the period of darkness. Identical letters indicate points that are significantly different at $P \leqslant 0.05$. Values are means \pm S.E.M.; $N=4-6$ for each time point.

(Fig. 4A). Cholesterol (Chol) levels peaked twice, between 18:00 h and 22:00 h and again at 06:00 h, and were relatively low at 02:00h. The amount of cholesterol decreased in the period of torpor between 10:00 $\mathrm{h}$ and 14:00 h. Cholesterol levels were lowest at 14:00 h, when they averaged around $0.06 \mathrm{mg} \mathrm{g}^{-1}$ dry lung mass. The ratios Chol/PL and Chol/DSP did not change significantly over the course of $24 \mathrm{~h}$ (Fig. 4B,C).

\section{Discussion}

\section{Metabolic measurements}

N. geoffroyi experienced two separate periods of activity interspersed with a short bout of torpor during the dark period at $02: 00 \mathrm{~h}$ and a more pronounced bout of torpor during the light period (Fig. 1). The activity rhythm of $N$. geoffroyi is largely determined by food availability (Ellis et al., 1991). $N$. geoffroyi use a variety of different cues to sense the availability of food, one of the most important being sounds made by the prey (Grant, 1991; Hosken et al., 1994). In this experiment, food was always available, so that the increases in activity at dawn and dusk reflect the natural activity cycle of $N$. geoffroyi, entrained to the dawn and dusk activity of its insect prey. At 02:00 h, $N$. geoffroyi became less active, and at this time approximately $70 \%$ were observed as torpid. The fact that metabolic rate was elevated relative to $T_{\mathrm{b}}$ at this time may reflect the increase in metabolic rate and thermal conductance that occur after the evening feed.

The $\dot{V}_{\mathrm{O}_{2}}$ values obtained in this study were consistently higher than those obtained by Hosken and Withers (1999) in their study of $N$. geoffroyi (Fig. 2B). Differences in the results between these two studies may reflect different experimental protocols. In their study, $N$. geoffroyi were starved for $12 \mathrm{~h}$ and held within the metabolic chamber for a minimum of $20 \mathrm{~min}$ before any metabolic measurements were taken. In contrast, the bats in the present study were not post-absorptive, and feeding would have increased their metabolic rate markedly.

\section{Diurnal changes in surfactant lipids}

\section{Phospholipids}

The elevated amounts of alveolar PL and DSP achieved during arousal from torpor were maintained throughout the dark phase (Fig. 3A,B), reflecting an increased rate of surfactant turnover and an upregulation of the entire surfactant system. The turnover rate did not decline when the bats entered a brief torpor period from $22: 00 \mathrm{~h}$ to $06: 00 \mathrm{~h}$ despite the decreases in $T_{\mathrm{b}}$ and metabolic rate recorded during this time. The metabolic effects of the evening feed may have maintained metabolic rate at a level high enough to maintain a relatively high rate of surfactant turnover. An increased turnover rate ensures that the surfactant system is capable of responding rapidly to physiological changes. The maintenance of elevated levels of PL and DSP is likely to have counteracted any decrease in lung compliance that may have resulted from the decrease in $T_{\mathrm{b}}$.

For $N$. geoffroyi, torpor during the day was accompanied by a decrease in the amount of alveolar PL and DSP (Fig. 3A,B); this is likely to be a direct reflection of the decrease during torpor in metabolic rate, ventilation and catecholamine levels compared with warm-active levels. The response of the surfactant system contrasts directly with that of $S$. crassicaudata (Langman et al., 1996), in which torpor was associated with an increase in PL and DSP content. Torpor in $S$. crassicaudata was induced by very low ambient temperatures $\left(10^{\circ} \mathrm{C}\right)$ and starvation $(16 \mathrm{~h})$ (Langman et al., 1996) and, hence, may be associated with elevated levels of cortisol, which are known to stimulate surfactant synthesis (Haagsman and Van Golde, 1991). Alternatively, the low body temperature and metabolic rate may lead to slower rates of 


\section{N. C. SLOCOMBE AND OTHERS}

surfactant re-uptake into type II cells and, hence, an accumulation in the alveolar space.

In terms of lung function, it is unclear why levels of PL and DSP should decrease during torpor. During torpor, the need to maintain alveolar stability is presumably as great or even greater than in the warm-active state, given the episodic breathing pattern (Szewczak and Jackson, 1992) and the consequently uneven rate and pattern of alveolar ventilation. Lung compliance must be maintained to facilitate alveolar expansion during the breathing bouts, and the surface-tensionlowering effect of surfactant is needed to prevent oedema. Oedema is a real problem if lung volumes are reduced during torpor and the fluid pressure at the corners of the alveoli is very high. Perhaps, in torpid $N$. geoffroyi, the alveoli are never inflated sufficiently to reach the dimensions attained in the warm-active state. The lower levels of surfactant may reflect the reduced alveolar surface area to be covered and the lower amounts of surfactant required to fulfil the roles described. Reduced inflation of alveoli during torpor may result from the increased stiffness of the lung tissue associated with the lower body temperatures as well as the decrease in ventilation characteristic of the torpid state.

In contrast to $S$. crassicaudata (Langman et al., 1996), torpor in $N$. geoffroyi was not accompanied by an increase in the DSP/PL ratio (Fig. 3C). The fact that the surfactant system of $N$. geoffroyi responded differently to that of $S$. crassicaudata may reflect the different physiological changes experienced by the animals throughout their torpor bouts. The torpid $T_{\mathrm{b}}$ of $S$. crassicaudata was $12-15^{\circ} \mathrm{C}$ (Langman et al., 1996), compared with $25^{\circ} \mathrm{C}$ in $N$. geoffroyi. At lower temperatures, apnoeic periods become longer (Szewczak and Jackson, 1992) and an increased proportion of surfacetension-lowering agent may be needed to stabilise the alveoli at very low lung volumes. At the higher torpid $T_{\mathrm{b}}$ of $N$. geoffroyi, the changes in lung volume may not have been great enough to elicit a change in DSP/PL.

\section{Cholesterol}

Unlike all other animals studied so far, the level of cholesterol in N. geoffroyi decreased during torpor (Fig. 4). In both lizards and dunnarts, a decrease in $T_{\mathrm{b}}$ was associated with an increase in cholesterol content, presumably to maintain surfactant homeoviscosity (Daniels et al., 1990; Langman et al., 1996). The present study suggests that, for $N$. geoffroyi, cholesterol does not function to maintain the fluidity of surfactant at low body temperatures. Cholesterol levels must increase, not decrease, to interfere with the close packing of phospholipids (Hadley, 1985). Why cholesterol levels decrease during torpor is not known. In this bat, cholesterol may be a passive component of the surfactant during torpor, without a particular function in lowering or controlling surface tension.

The mechanisms controlling the amount of cholesterol in pulmonary surfactant are largely unknown. In $N$. geoffroyi, cholesterol levels appear to follow the changes in $T_{\mathrm{b}}$ passively. Temperature would have a direct influence on the amount of surfactant cholesterol if, like the surfactant phospholipids, it is released from the type II cell by exocytosis. As temperature increases, so too would enzyme activity and the rate of many subcellular molecular interactions involved in the process of exocytosis, ultimately increasing the rate of fusion with the plasma membrane.

$N$. geoffroyi had 15 times less cholesterol than both the dunnart $S$. crassicaudata and the mouse (Langman et al., 1996). These are the lowest absolute and relative amounts of surfactant cholesterol in any mammal studied to date. The low levels of cholesterol recorded in the surfactant of $N$. geoffroyi may relate to the size of the alveoli in bats. The air spaces are finely subdivided such that the alveolar diameter is smaller than that of most other mammals (Maina et al., 1982; Maina and King, 1984). It is possible that the volume of the alveoli, while able to increase markedly from rest to flight, remains small enough throughout its cycle of inflation and deflation to require no 'spreading' component in the surfactant. If this is the case, the surfactant present in the alveoli could adequately cover the relatively small surface area of the alveoli without the need for surfactant cholesterol.

It is also possible that the low proportion of surfactant cholesterol in $N$. geoffroyi represents an adaptive strategy to help maximise the surface activity of the surfactant. Cholesterol, while improving film respreading, also limits the minimum surface tension obtainable during compression because the sterol cannot be squeezed out easily from DPPC/cholesterol spread films (Hildebran et al., 1979). This bat may have evolved other means to maintain the fluidity and spreadability of surfactant. The surfactant proteins (SPs) enhance adsorption rate by interacting with the phospholipids. While the nature of these protein-lipid interactions is unknown, SP-B and SP-C, as well as the hydrophilic protein SP-A, have all been shown to increase the rate of monolayer formation at an air-liquid interface (Veldhuizen et al., 1998). It appears that the surfactant proteins could be playing a crucial role in regulating surfactant fluidity and spreadability in these bats.

The authors would like to thank Terry Reardon (SA Museum) and Kate Davidson for assistance in the field and laboratory. This work was funded by the Australian Research Council (ARC) Large Grant Scheme to C.B.D. and an ARC Research Fellowship to S.O. All experiments were performed under Adelaide University Ethics Committee approval number M/55/98 and SANPWS permit number W24091-1.

\section{References}

Brown, L. S. and Longmore, W. J. (1981). Adrenergic and cholinergic regulation of lung surfactant secretion in the isolated perfused rat lung and in the alveolar type II cell in culture. J. Biol. Chem. 256, 66-72.

Daniels, C. B., Barr, H. A., Power, J. H. T. and Nicholas, T. E. (1990). Body temperature alters the lipid composition of pulmonary surfactant in the lizard Ctenophorus nuchalis. Exp. Lung Res. 16, 435-449.

Doyle, I. R., Jones, M. E., Barr, H. A., Orgeig, S., Crockett, A. J., 
McDonald, C. F. and Nicholas, T. E. (1994). Composition of human pulmonary surfactant varies with exercise and level of fitness. Am. J. Resp. Crit. Care Med. 149, 1619-1627.

Ellis, W. A. H., Marples, T. G. and Phillips, W. R. (1991). The effects of a temperature-determined food supply on the annual activity cycle of the lesser long-eared bat, Nyctophilus geoffroyi Leach, 1821 (Microchiroptera: Vespertilionidae). Aust. J. Zool. 39, 263-271.

Frappell, P. B. and Daniels, C. B. (1991). Temperature effects on ventilation and metabolism in the lizard, Ctenophorus nuchalis. Respir. Physiol. 86, 257-270.

Goerke, J. (1998). Pulmonary surfactant: functions and molecular compositon. Biochim. Biophys. Acta 1408, 79-89.

Grant, J. D. A. (1991). Prey location by two Australian long-eared bats, Nyctophilus gouldii and N. geoffroyi. Aust. J. Zool. 39, 45-56.

Haagsman, H. P. and Van Golde, L. M. G. (1991). Synthesis and assembly of lung surfactant. Annu. Rev. Physiol. 53, 441-464.

Hadley, N. F. (1985). The Adaptive Role of Lipids in Biological Systems. New York: J. Wiley \& Sons.

Hildebran, J. N., Goerke, J. and Clements, J. A. (1979). Pulmonary surface film stability and composition. J. Appl. Physiol. 47, 604-611.

Hosken, D. J., Bailey, W. J., O'Shea, J. E. and Roberts, J. D. (1994). Localisation of insect calls by the bat Nyctophilus geoffroyi (Chiroptera: Vespertilionidae): a laboratory study. Aust. J. Zool. 42, 177-184.

Hosken, D. J. and Withers, P. C. (1999). Metabolic physiology of euthermic and torpid lesser long-eared bats, Nyctophilus geoffroyi (Chiroptera: Vespertilionidae). J. Mammal. 80, 42-52.

Langman, C., Orgeig, S. and Daniels, C. B. (1996). Alterations in composition and function of surfactant associated with torpor in Sminthopsis crassicaudata. Am. J. Physiol. 271, R437-R445.

Lopatko, O. V., Orgeig, S., Palmer, D. and Schurch, S. (1999). Alterations in pulmonary surfactant after rapid arousal from torpor in the marsupial Sminthopsis crassicaudata. J. Appl. Physiol. 86, 1959-1970.

Maina, J. N. and King, A. S. (1984). Correlations between structure and function in the design of the bat lung: a morphometric study. J. Exp. Biol. 111, 43-61.

Maina, J. N., King, A. S. and King, D. Z. (1982). A morphometric analysis of the lung of a species of bat. Respir. Physiol. 50, 1-11.
Orgeig, S., Barr, H. A. and Nicholas, T. E. (1995). Effect of hyperpnea on the cholesterol to disaturated phospholipid ratio in alveolar surfactant of rats. Exp. Lung Res. 21, 157-174.

Possmayer, F. (1991). Biophysical activities of pulmonary surfactant. In Fetal and Neonatal Physiology (ed. R. A. Polin and W. W. Fox), pp. 459-962. Philadelphia: W. B. Saunders Co.

Speakman, J. R. (1988). Position of the pinnea and thermoregulatory status in brown long-eared bats (Plecotus auritus). J. Therm. Biol. 13, 25-29.

Szewczak, J. M. and Jackson, D. C. (1992). Apneic oxygen uptake in the torpid bat, Eptesicus fuscus. J. Exp. Biol. 173, 217-227.

Thomas, S. P. (1981). Ventilation and oxygen extraction in the bat Pteropus gouldii during rest and steady flight. J. Exp. Biol. 94, 231-250.

Thomas, S. P., Lust, M. R. and VanRiper, H. J. (1984). Ventilation and oxygen extraction in the bat Phyllostomus hastus during rest and steady flight. Physiol. Zool. 57, 237-250.

Veldhuizen, R. A. W., Nag, K., Orgeig, S. and Possmayer, F. (1998). The role of lipids in pulmonary surfactant. Biochim. Biophys. Acta 1408, 90-108.

Wirtz, H. R. W. and Dobbs, L. G. (1990). Calcium mobilization and exocytosis after one mechanical stretch of lung epithelial cells. Science 250, 1266-1269.

Wood, P. G., Andrew, L. K., Daniels, C. B., Orgeig, S. and Roberts, C. T. (1997). Autonomic control of the pulmonary surfactant system and lung compliance in the lizard. Physiol. Zool. 70, 444-455.

Wood, P. G., Daniels, C. B. and Orgeig, S. (1995). Functional significance and control of release of pulmonary surfactant in the lizard lung. Am. J. Physiol. 269, R838-R847.

Wood, P. G., Lopatko, O. V., Orgeig, S., Codd, J. R. and Daniels, C. B. (1999). Control of pulmonary surfactant secretion from type II pneumocytes isolated from the lizard, Pogona vitticeps. Am. J. Physiol. 277, R1705-R1711.

Wood, P. G., Lopatko, O. V., Orgeig, S., Joss, J. M. P., Smits, A. W. and Daniels, C. B. (2000). Control of pulmonary surfactant secretion: An evolutionary perspective. Am. J. Physiol. 278, R611-R619.

Wright, J. R. and Clements, J. A. (1989). Lung surfactant turnovers and factors that affect turnover. In Lung Cell Biology (ed. D. Massaro), pp. 655-699. New York: Marcel Dekker Inc. 